Filo. y Linguí.7(1 y2):43-48,1981.

\title{
LOS ESTILOS INDIRECTO Y DIRECTO LIBRES: UN APORTE A SU DEFINICION
}

Ma. Elia Rodríguez Herrera* Carmen Ma. Valverde Acosta**

La crisis de la novela contemporánea, que es reflejo de la crisis mundial en los aspectos políticos, económicos, filosóficos, religiosos, morales, se manifiesta no solamente en el plano de la historia con la incorporación de los diferentes contextos, sino también y muy especialmente, en los recursos lingüísticos empleados en el relato.

En ambos campos existen numerosos estudios sobre las literaturas de diferentes países. Sin embargo, algunos recursos no han sido objeto predilecto de la crítica por lo que la bibliografía es escasa, ambigua o aún contradictoria. Tal es el caso del modo de reproducción en el relato de las palabras o pensamientos de los personajes; lo cual constituye uno de los signos más claros del rompimiento con las normas lingüísticas tradicionales:

Pretendemos en este artículo reunir las diferentes opiniones sobre el tema, a la vez que sistematizarlas con el planteamiento de nuestra propia definición, puesto que consideramos que será un aporte útil y clarificador.

Desde los escritores latinos se hacía la distinción entre estilo directo y estilo indirecto. Al primero lo llamaban "oratio recta" y al segundo, "oratio obliqua". Esta norma se conservó hasta el siglo pasado y podemos decir que aún hoy se mantiene aunque enriquecida con otros conceptos fundamentalmente en lo que se refiere a la reproducción del pensamiento.

El estilo directo consiste en reproducir "textualmente" las palabras o pensamientos de los personajes, lo cual da lugar al diálogo 0 al monólogo o soliloquio, en el caso de la palabra, y al monólogo interior cuando se trata de pensamientos. Esta reproducción textual de pensamientos o palabras se refleja, por supuesto, en la sintaxis del relato. Se da en primera persona,

* Lic. Ma. Elia Rodríguez H., Instructora Licenciada del CUO.

** Lic. Carmen Ma. Valverde A., Profesora Adjunta del CUO. antecedida por verbos introductores o algún signo, como los dos puntos y los guiones, en el caso del lenguaje articualado. En el monólogo interior se han utilizado las comillas, un tipo diferente de letra, espaciación tipográfica y, en algunas ocasiones, simplemente la pausa del punto.

El estilo indirecto se da al reproducirse las palabras y pensamientos de los personajes en la boca del narrador mediante la subordinación sintáctica: hay un verbo introductor seguido de una partícula subordinante y la oración subordinada, que reproduce las palabras o pensamientos cambia los modos y tiempos verbales, de los que usó el personaje a los propios de una oración subordinada, según las normas gramaticales.

A principios de este siglo se comienza a hablar del estilo indirecto libre y es el francés Bally quien inicia una polémica sobre el tema en 1912 con la publicación del libro L'style indirect libre en français moderne.

Guillermo Verdín Díaz resume esa polémica en su "Introducción al estilo indirecto libre en español".

En la polémica participaron varios lingüistas (Kalepky, Tobler, Lorck, Lerch, Hoas, Herdin, Laftman, Mennicken, etc.), quienes forman dos grupos, uno francés y otro alemán.

La preocupación básica que se refleja en la polémica es de carácter morfosintáctico; uso de tiempos verbales, papel del condicional, construcciones especiales, etc.

De sus estudios se deduce asimismo, que se refieren en forma parcial e incompleta al tema.

Consideramos que a esta fecha aún no se ha aclarado totalmente ese concepto puesto que se ha pretendido aclararlo tomando como único punto de vista el gramatical y no se han considerado otros aspectos tales como la perspectiva del narrador.

Se ha definido el estilo indirecto libre como la mezcla del directo y el indirecto pero en las opiniones de los críticos no queda claro en qué consiste esa mezcla. 
Revisemos algunas definiciones. Guillermo Verdín Díaz dice que es:

"La incorporación del diálogo a la narración con la misma sintaxis que el indirecto puro, pero independientemente de verbos introductores y nexos que indiquen subordinación o dependencia" (1).

Creemos que esta definición deja por fuera otra modalidad que puede darse en el estilo indirecto libre y que será comentada más adelante.

Oito Jespersen lo llama estilo representado y considera que es una de las dos modalidades del estilo indirecto. Manifiesta que:

"Principalmente se usa en largas narraciones continuadas en las que la relación de los sucesos en el mundo exterior queda interrumpida muchas veces sin ninguna transición del tipo de "dijo" o "pensó" por una transcripción de lo que la persona citada estaba diciendo o pensando en aquel momento determinado, como si dichas palabras o pensamientos fuesen la continuación inmediata de los acontecimientos anteriores. El escritor no experimenta o "vive" dichos pensamientos o palabras, pero las representa, de ahí el nombre que ha escogido" (2).

Explica que le da este nombre porque:

"No es fácil encontrar un nombre adecuado para describir el estilo indirecto de este tipo. Lorck rechaza con razón el término de Tobler, según el cual se trata de una mezcla de estilo directo e indirecto, y el de Kalepky, quien habla de verschleierte Rede ("estilo velado") y el de Bally, quien lo llama "estilo indirecto libre", pero el nombre que él le da "erlebte Rede" ("estilo vivido"), no parece mucho mejor. No he encontrado nombre mejor que el de "estilo representado" que corresponde al alemán "vorgestellte Rede" y al danés "forestillettalo" (3).

A nuestro juicio Jespersen omite en su deinnciun criterios gramaticales que la harían más clara y precisa.

Por su parte, W. Kayser propone que:

"El estilo indirecto libre se encuentra entre el estilo indirecto y el directo, precisamente en medio. "¿Debo ir por la noche al teatro?". Así podría reproducir directamente el narrador el pensamiento de uno de sus personajes, poniendo al personaje $\mathrm{y}$ al lector en estrecho contacto.

En la reproducción indirecta, el narrador conservaría las riendas y serviría de mediador entre el lector y el personaje: "Pensaba si debía ir por la noche al teatro". El estilo indirecto libre ocupa un lugar intermedio: “¿Debía ir por la noche al teatro?". El narrador, en este caso es menos visible que en el estilo indirecto; el foco de la perspectiva casi pasa al alma del propio personaje, como si el lector se asomase directamente a su vida interior" (4).

A pesar de que, al mencionar el foco de la narración aclara en buena parte la idea, al igual que Jespersen omite criterios gramaticales que diluciden el asunto.

Nosotros consideramos que es necesario incluir y considerar en la definición los dos aspectos.

Analicémoslo en un texto:

"Reaparece el Tyrk, más borracho que truhán de almadraba, anunciado que ha encontrado enormes viñedos silvestres, y que las uvas, puestas a fermentar, dan un vino que, bueno, con verme basta, y aquí no me tose nadie, y que me dejen dormir la mona, que esto es Jauja (...) ... Y se desploma y vomita y grita que todos los normáns son unos hijos de puta ...(5).

En este ejemplo el relato está dado por el narrador pero, a partir del verbo introductor "anunciando" reproduce en primera instancia indirectamente las palabras del personaje Tyrk y en segunda instancia el foco de la narración se traslada momentáneamente a ese personaje pues se reproducen en forma directa sus palabras.

Decimos que las palabras están introducidas indirectamente pues así lo demuestran los aspectos gramaticales: verbo en $3^{\mathrm{a}}$ persona singular, o sea, 
el narrador repite lo que anunció el personaje con las palabras del narrador.

Decimos que se reproducen en forma directa las palabras del personaje porque así lo demuestran los aspectos gramaticales: verbos en $1^{\mathrm{a}}$ persona singular, es decir el narrador repite las palabras del personaje con las palabras del personaje.

Vemos así que los aspectos gramaticales hacen que el foco de la narración, aunque no la narración misma, se traslade fácilmente del hablante básico al personaje.

Veamos otro ejemplo:

"Da la vuelta a la Plaza, al entrar a la colmena detiene un taxi: ¿su perrito no iría a ensuciar el asiento? No maestro, no lo iba a ensuciar" (6).

En este ejemplo tenemos la misma situación que en el anterior: el foco narrativo se traslada al personaje pero la reproducción de sus palabras no está antecedida por ninguna partícula ni verbo introductor. Sabemos que es el narrador quien habla porque las palabras del personaje están dadas indirectamente $\mathrm{y}$ esto lo muestran las formas verbales.

En definitiva podemos concluir de las anteriores definiciones y con los ejemplos analizados que en el estilo indirecto libre el narrador mantiene el hilo de la narración pero la alteración de las formas gramaticales pueden hacer pensar que el narrador se ha alejado. En el primer ejemplo porque se reproducen "textualmente" las palabras del personaje pero la voz del narrador se mantiene a través del verbo y la partícula introductoria.

En el segundo ejemplo la carencia del verbo introductor y partícula subordinante y el uso de signos de interrogación y admiración y la pausa que precede al enunciado, propias del estilo directo, hacen sentir al lector que el narrador ha cedido la palabra al personaje. Sin embargo, la sintaxis de ese enunciado, los modos y tiempos verbales, son los propios del estilo indirecto, por lo que siempre se siente la voz del narrador.

Con base en todo lo anterior consideramos importante resumir en forma integrada las ideas contenidas en las definiciones revisadas.

Entenderemos, pues, como estilo indirecto libre la reproducción de palabras o pensamientos de los personajes con la misma sintaxis que el indirecto puro sin que existan verbos introductores ni partículas subordinantes; 0 , con la misma sintaxis del directo pero con verbos introductores y partículas subordinantes que anteceden al enunciado mimético. Como ya se analizó, ambas modalidades hacen que el foco narrativo se traslade momentáneamente a los personajes sin que el narrador pierda el hilo narrativo.

Recientemente los novelistas han utilizado otra modalidad de incorporación del lenguaje y pensamientos de los personajes llamada "estilo directo libre" por Santos Sanz Villanueva (7) y William Hendricks (8). Con esta modalidad el narrador reproduce los pensamientos y palabras de los personajes sin que medien los signos, espacios, nexos verbales o pronominales propios del estilo directo. Veamos algunos ejemplos:

“... pero a él no le importaba la insolencia de Patricio Aragonés a quien puse a vivir como un rey en un palacio y te dí lo que nadie le ha dado a nadie en este mundo hasta prestarle mis propias mujeres, aunque mejor no hablemos de eso mi general que vale más estar capado a mazo que andar tumbando madres por el suelo como si fuera cuestión de herrar novillas ..." (9).

Como vemos en este ejemplo la voz del relato es la del hablante básico y sin mediación de ningún signo, espacio o nexo verbal se reproducen las palabras del Patriarca primero y de Patricio Aragonés después, como si el narrador les cediera la palabra o como si ellos se la arrebataran.

Igualmente sucede en este otro fragmento:

"La casa se volvió un desbarajuste, la señora sólo hablaba de sus ensayos y se puso a régimen, a mediodía un juguito de toronja y un bistec a la parrilla, en la noche una ensaladita sin aderezar, me muero de hambre pero que importa, cierren las ventanas, las puertas, si me resfrío antes del debut me muero, iba a dejar de fumar, el cigarrillo era veneno para una artista" (10).

Aquí las palabras de "la señora" se intercalan textualmente, directamente para completar la explicación del narrador.

Definiremos entonces como estilo directo libre la incorporación del coloquio y del pensamiento de los personajes a la narración, de la misma forma que lo hace el estilo directo simple pero sin utilizar las convenciones, ya sean de 
puntuación o tipográficas, de este estilo.

Cabe advertir, sin embargo, que la reproducción de la interioridad de los personajes puede constituir el estilo directo libre propiamente o bien constituir un monólogo interior. Este es definido por Humphreay como una de las técnicas que utiliza la llamada novela de la corriente de la conciencia:

"La forma más sencilla de identificar una novela de corriente de la conciencia es atendiendo a su argumento. Este la caracteriza más que su técnica, su intención o su tema tienen como argumento esencial la conciencia de uno o más personajes; es decir que la conciencia descrita hace las veces de pantalla sobre la cual se proyecta el material que aparece en la novela" (11).

Respecto a la técnica del monólogo anterior:

"Se trata de una técnica para representar el contenido síquico de sus procesos a los varios niveles del control consciente, es decir, que se trata de representar la conciencia. Conviene subrayar, sin embargo, que puede referirse a cualquier nivel de ella (no es precisa, es más no es habitual, una expresión del pensamiento más íntimo que se halla cerca del inconsciente) y que trata de los contenidos y de los procesos de la conciencia no de uno de esos dos elementos únicamente. Y debe tenerse en cuenta también que son parcial o totalmente inarticulados pues presentan el contenido de la conciencia en su estado incipiente, antes de que haya sido formulado oralmente" (12).
Aunque el monólogo interior no es exclusivo de la novela de la corriente de la conciencia, sino que se ha convertido en una técnica bastante común en la novela contemporánea, sí consideramos que para ser tal debe guardar ciertos elementos como es el hecho de la representación de la conciencia o subconciencia, lo cual se traduce lingüisticamente en una falta de lógica en el discurso debido a la libre asociación de ideas, y para lograr todo esto, fundamentalmente debe tener cierta extensión. Además, este monólcgo interior puede ser expresado mediante el estilo directo, el indirecto, el directo libre o el indirecto libre, dando lugar al monólogo interior directo o indirecto según Humphrey (13). Lo fundamental es la voluntad de representar el contenido psíquico y sus procesos. De ahí las características que le hemos señalado como básicas.

Así pues, aclarada esta otra técnica, restringimos nuestra definición de estilo directo libre únicamente a la expresión esporádica de pensamientos, o, por supuesto, de palabras.

Queda así expuesto un panorama de lo que la crítica ha dado entorno a la reproducción de pensamientos y palabras de los actores en el relato.

Estimamos que nuestras opiniones y análisis permiten concluir que:

1.- Los críticos que han estudiado los estilos directo e indirecto libres abordan el problema en forma parcial e incompleta.

2.- Deben tenerse presentes, para comprender estos recursos en su totalidad, no sólo criterios gramaticales sino también de perspectiva narrativa.

3.- El uso de los estilos directo e indirecto libres es un recurso fundamental en la narrativa contemporánea que permite relfejar más claramente la riqueza expresiva del relato.

4.- Consideramos asimismo que con este estudio hemos contribuido a sistematizar y poner en claro los conceptos fundamentales de este asunto. 


\section{NOTAS}

(1) Guillermo Verdín Díaz. Introducción al estilo indirecto libre en español. (Madrid Revista de Filología Española Anejo XCI, C.S.I.C. 1970) p. 80

(2) Otto Jespersen. La Filosofía de la Gramática. (Barcelona Anagrama, 1975) p. 351

(3) Loc. cit.

(4) Wolphgang Kayser. Interpretación y análisis de la obra literaria. (4a. ed. Madrid, Gredos, 1970) p. 192

(5) Alejo Carpentier. El arpa y la sombra. (6a. ed., México Siglo XXI Editores, 1980) págs. 67-68

(6) Mario Vargas Llosa. Conversación en la Catedral. (9a. ed. Barcelona: Seix Barral, 1976) p. 30
(7) Santos Sanz Villanueva. Tendencias de la novela española. (Madrid cuadernos para el diálogo, 1972) p. 273

(8) William Hendricks. Semiologia del discurso literario. (Madrid Catedra 1976) págs. 52-53

(9) Gabriel García Márquez. El otoño del patriarca. (Buenos Aires: Sudamericana, 1975)

(10) Mario Vargas Llosa. Op. cit. p. 454

(11) Robert Humphrey. La corriente de la conciencia en la novela moderna. (Santiago, editorial Universitaria, 1969) págs. 11-12

(12) Op. cit. P. 36

(13) Ibid. págs. 35-71

\section{BIBLIOGRAFIA}

Alberes, M. Historia de la novela moderna. México: Uthea, 1966.

Amorós, Andrés. Introducción a la novela contemporánea. Salamanca: Anaya 1966.

Baquero G., M. Estructuras de la novela actual 3a. ed. Barcelona: Planeta, 1975.

Baquero Goyanes, M. ¿Qué es la novela? 3a. ed. Buenos Aires: Columba 1975.

Barthes, R. et alt. Análisis estructural del relato. 3a. ed. Tr. Beatriz Dorriots. Buenos Aires: Tiempo Contemporáneo. 1974.

Bourneuf, R. y Ouellet, R. La novela. Tr. Enric Sullá. Barcelona: Ariel, 1975.

Buckley, Ramón. Problemas formales de la novela española contemporánea. 2a. ed. Barcelona: Ed. Península 1973.

Carpentier, Alejo. El arpa y la sombra. 6a. ed. México: Siglo XXI Editores. 1980.
García Márquez, Gabriel. El otoño del patriarca Buenos Aires: Sudamericana. 1975.

Genette, Gerard. Figures III. París, Editions du Seuil 1972.

Gullón, G. y Gullón, A. Teoría de la novela. Madrid: Tawnus, 1974.

Hendricks, William. Semiologia del discurso literario. Tr. J. A. Millón. Madrid: Cátedra 1976.

Humphrey, Robert. La corriente de la conciencia en la novela moderna. Tr. Julio Rodríguez Puértolas y Carmen Criado Santiago: Editorial Universitaria, 1969.

Jespersen, Otto. La filosofía de la gramática. Tr. Carlos Manzano. Barcelona: Anagrama, 1975.

Kayser. W. Interpretación y análisis de la obra literaria. 4a. ed. Tr. Madrid. Gredos, 1970.

Sanz Villanueva, Santos. Tendencias de la novela española actual. Madrid. Cuadernos para el diálogo 1972. 
Sobejano, Gonzalo. Novela española de nuestro tiempo. 2a. ed. Madrid. Prensa española, 1970.

Todorov, Tzvetan. Literatura y significación. Barcelona. Planeta. 1967.
Vargas Llosa, Mario. Conversación en la Catedral. 9a. ed. Barcelona. Seix Barral. 1976.

Verdín Díaz, G. Introducción al estilo indirecto libre en español. Madrid: Revista de Filología Española Anejo XCI C.S.I.C. 1970. 